Опираясь на данные, полученные в ходе исследования, можно утверждать, что современная молодежь хорошо информирована, обладает довольно обширными знаниями о содержании культуры своего этноса, однако гуманистический потенциал этнокультуры остается нереализованным в практике повседневной жизни. Это должно хоть в какой-то степени быть восполнено возможностями современного образовательного процесса в школе и вузе [5, 6]. На наш взгляд, необходим поиск таких решений в сфере образования, которые позволили бы обеспечить сохранность культурных ценностей каждого этноса, так как именно этнокультурное наследие - это то, что позволяет сохранить принадлежность человека к определенному социокультурному пространству и обеспечивает чувство малой Родины.

$$
* * *
$$

1. Арутюнов, С.А. Культурная антропология. - М., 2004. - 216 с.

2. Арутюнов, С.А. Инновации в культуре этноса и их социально-экономическая обусловленность // Этнографические исследования развития культуры. - М.: Наука, 1985. - С.31 - 49.

3. Богдасарова, А.Б. Инкорпорация этнокультурных ценностей в контекст современного образовательного процесса // Социально-гуманитарные знания. - 2007. - № 6. - С. 42 - 51 .

4. Вязникова, Л.Ф. Ценности в образовании: выбор пути развития // Психологическая наука и образование. - 2002. - № 4. - С. 88-98.

5. Егошина Н. Г. Этнокультурные ценности как основа аксиологизации современного образования // Научное мнение: научный журнал / Санкт-Петербургский университетский кон $\neg$ сорциум. — СПб., 2020. — № 6. - C. 47 - 51 .

6. Егошина, Н.Г. Этнокультурное образование в Республике Марий Эл: опыт, сложности, перспективы// Языки и литературы в поликультурном пространстве: современное состояние и перспективы развития: сборник материалов Международной научно-практической конференции. Уфа: РИЦ БашГУ, 2020. - С.159 - 166.

7. Кирьякова, А.В. Ценностные ориентиры университетского образования/ А.В. Кирьякова// Вестник ОГУ. - 2011. - №2 (121). - С. 27 - 33.

8. Магранов, А.С., Деточенко, Л.С. Граждансая идентичность современной студенческой молодежи: особенности и факторы трансформации// Социологичсекие исследования. - 2018. - №8. - С. 108 106.

9. Першиц, А.И. Возможен ли информационный подход к социальным ценностям этнической культуры? // Этнографические исследования развития культуры. - М.: Наука, 1985. - С. 50 - 63.

10. Этнические процессы в современном мире /под ред Ю.В. Бромлей. - М.: Наука, 1987. - 445 с.

\title{
Захарова Т.В., Шабунова А.А. \\ Особенности исследования социального здоровья у детей младшего школьного возраста с ограниченными возможностями здоровья
}

ФГБОУ ВО «Череповеиякий государственный университет»

doi 10.18411/gq-15-10-2021-06

(Россия, Череповеи)

\section{Аннотация}

В статье обращается внимание на важность формирования социального здоровья детей. Авторы обозначают, что проблемой является подбор инструментария, позволяющего на ранних этапах выявить факторы, снижающие социальное здоровье и благополучие младших школьников с ограниченными возможностями здоровья. В статье представлены основные результаты проведенного исследования социального здоровья младших школьников с ограниченными возможностями здоровья и детей с нормотипичным развитием.

Ключевые слова: социальное здоровье, дети с ограниченными возможностями здоровья, инструментарий.

\section{Abstract}

The article draws attention to the importance of developing the social health of children. The authors point out that the challenge is to find tools that allow early identification 
of factors that reduce the social health and well-being of young schoolchildren with disabilities. The article presents the main results of the social health research carried out on children with special needs and children with normal development.

Keywords: social health, children with special needs, tool.

Гармоничное существование детей в социальной среде возможно лишь при условии взаимопроникновения ребенка и социума. Для этого необходима интеграция личности в общество, а также удовлетворенность общества поведением и ценностями ребенка [3]. Условия среды воспитания во многом обусловливают социальное развитие детей и возможности укрепления их физического и социального здоровья. Л.С. Выготский [1] подчеркивает, что наличие дефекта в развитии у детей с ограниченными возможностями здоровья (OB3) не влияет на их социальное развитие, а воздействует на различные компоненты психического и социального развития через возникновение «социального вывиха». Н.В. Голицина считает, что у детей с ОВЗ возникают проблемы с психосоциальной адаптацией, а также с формированием основных механизмов социализации, следовательно, и с социальным здоровьем в целом [2]. Поэтому коррекционная педагогика и специальная психология должны быть направлены на профилактику нарушений социального здоровья детей с OB3, на обеспечение адаптации и социализации их к обществу. Это особенно важно в период адаптации к школьному обучению.

Для своевременного и грамотного вмешательства как коррекционным педагогам, так и учителям младших классов важно иметь достоверную информацию о возможных рисках, влияющих на формирование социального здоровья.

\section{Литературный обзор}

Проблеме выявления особенностей и рисков формирования социального здоровья детей младшего школьного возраста с ОВ3 посвящены многие исследования. Так Р.О. Дружинин, подчеркивая важность формирования социального здоровья, использует междисциплинарный подход и выделяет группы технологий социальной работы, способствующие сохранению социального здоровья детей. Среди них особую важность имеют диагностические (включая экспертизу, мониторинг социального положения детей), управленческие (воздействие на среду и личность), профилактические (в том числе, здоровьесберегающие технологии) [5].

Европейские исследователи особое внимание в формировании социального здоровья детей с ОВ3 придают инклюзивному образованию. При этом отмечают, что очень важно, чтобы учителя повышали свою квалификацию в отношении научно обоснованной практики инклюзивного образования, которая привела бы к успешному опыту учителей. А также необходима смена ценностных ориентиров в обществе на толерантное отношение к детям с особыми образовательными потребностями (важно для всех социальных групп: администрации, педагогов, родителей и детей) $[8,12,13$, $14]$.

Некоторые авторы для оценки социального здоровья использовали концепции оценки социальной интеграции. Камбра и Сильвестр (2003) полагались на "социализацию в группе сверстников" для измерения социальной интеграции детей (оценка социальных предпочтений и социального отвержения). Тейлор и Хоутон [15] использовали анализ дружеских отношений, чтобы оценить их уровень социальной интеграции. По мнению этих авторов, ребенок считается полностью социально интегрированным только в том случае, если у него есть три или более постоянных пар дружбы со сверстниками. Другие авторы (Флем, Келлер, Дюкетт) при обсуждении социальной интеграции и социального здоровья опираются на следующие индикаторы: 
дружеские отношения; самовосприятие учащихся, чувство принадлежности к школе, восприятие себя в школе, чувство одиночества; принятие сверстниками, восприятие сверстников, например, социальная поддержка, издевательства; и социальные взаимодействия со сверстниками и учителями, например, свободное время, совместные задания, участие в групповых / школьных мероприятиях и социальная изоляция $[9,10$, 11].

Многие исследователи (О.А. Денисова, О.Л. Леханова и др.) обращают внимание на важную роль семьи в социализации и формировании социального здоровья детей с ОВ3. В работах показано, что в семьях, воспитывающих детей с ОВ3 более низкий уровень общения, часто родители стесняются своих детей и не желают, чтобы в обществе знали о проблемах ребенка, либо чрезмерно опекают ребенка, сужая круг его общения и ограждая от посильной работы. Авторы подчеркивают, что неумение примириться с ситуацией и принять ребенка, неготовность к преодолению трудностей приводят к десоциализации не только детей с ОВ3, но и их родителей [4].

\section{Материалы и методы}

Цель исследования - выявление особенностей социального здоровья детей младшего школьного возраста с ограниченными возможностями здоровья в сравнении с нормотипично развивающимися детьми того же возраста.

Для достижения цели была разработана анкета, состоящая из двух блоков. Первый блок направлен на выявление социального неблагополучия путем сплошного анкетирования школьников и выявления групп риска. Второй блок - предполагает изучение уровня школьной мотивации.

Опрос проводился на базе БУ ВО «Областной центр ППМСП». Опрошено было 30 детей с ОВ3 и 31 нормотипично развивающийся ребенок. Результаты опроса обработаны с помощью статистического пакета SPSS Statistic.

\section{Результаты исследования}

Для выявления социального неблагополучия детей младшего школьного возраста в I блоке анкеты изучалось: материальное благополучие, состояние здоровья и защищенность, образование, отношение в семье и со сверстниками, поведенческие и средовые риски и самооценка детьми уровня своего благополучия.

Материальное благополучие.

Важным факторами формирования материального благополучия любой семьи выступают: трудовая занятость родителей, характеристика семьи (полная, неполная), число детей в семье, также влияет и совместное проживание с прародителями.

У всех детей, участвующих в исследовании, родители работали. Исследование выявило более высокие риски материального неблагополучия в семьях с детьми с ОВЗ. Так, например, среди детей с ОВ3 27,8\% воспитываются в неполных семьях $(20,7 \%$ нормотипичные дети). Кроме того, дети с ОВ3 чаще воспитываются в многодетных семьях (16,7\% у детей с ОВ3 в сравнении с $13,8 \%$ у контрольной группы). Несмотря на то, что большинство семей проживают отдельно от бабушек и дедушек $(74,5 \%)$, отметим, что семьи, воспитывающие детей с ОВ3, несколько реже проживают с прародителями.

Еще одним индикатором материального благополучия семьи, отражающемся как на развитии детей, так и на их школьных успехах, является наличие обустроенного места для занятий дома. Результаты опроса показали, что специальное место или стол для занятий есть у 77,8\% детей с ОВ3 (100\% нормотипичные дети); компьютер (ноутбук) для выполнения школьных заданий есть у 66,7\% детей с ограниченными возможностями здоровья (79,3\% нормотипичные дети); доступ в Интернет есть 83,3\% детей с ОВ3 (96,6\% нормотипичные дети, рис. 1). 


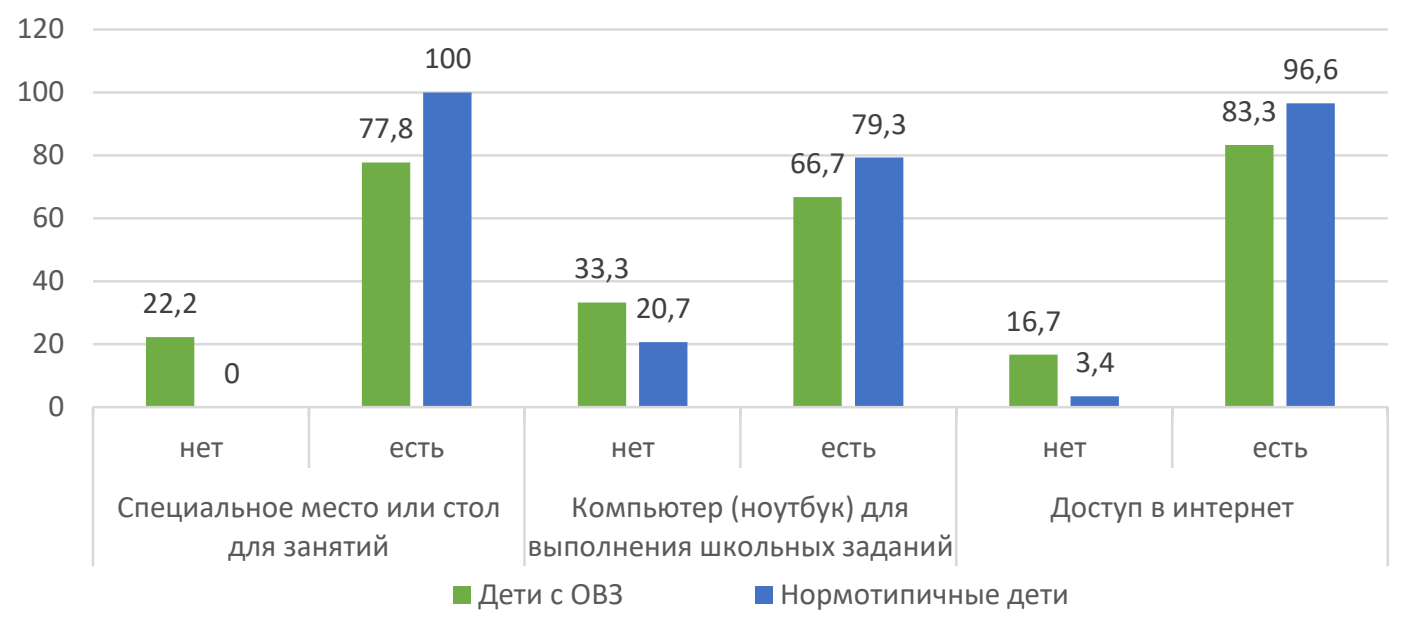

Рисунок 1. Обустройство места для занятий дома (в \% от числа опрошенньх)

\section{Состояние здоровья и защищщенность.}

Физическое здоровье является важным компонентом социального здоровья. В исследовании использовался метод самооценки. Дети оценивали свое здоровье по шкале от отличного до плохого. Анализ показал, что дети с OB3 чаще оценивают свое здоровье как хорошее $(61,1 \%)$, в то время как дети из контрольной группы оценивают свое здоровье как отличное $(51,7 \%)$. Также выявлено, что 5,6\% детей с ОВ3 оценили свое здоровье как плохое, в контрольной группе таких оценок нет.

Осознание важности заботы о здоровье и организация свободного времени для формирования здоровьесберегающих практик являются значимым компонентом в формировании социального здоровья. В семьях, воспитывающих детей с OB3, анализ выявил более низкий уровень здоровьесберегающих практик. Исследование показало, что дети с ОВ3 реже занимаются физкультурой и спортом $(61,1 \%)$, чем нормотипичные дети $(72,4 \%)$, а также реже соблюдают режим дня - 38,9\% (51,7\% нормотипичные дети, рис. 2). Оценивая свое питание нормотипичные дети в 1,7 раза чаще называют его правильным (27,8\% дети с ОВ3; 48,3\% нормотипичные дети). Важными моментами заботы о здоровье являются элементы самоконтроля, к которым можно отнести соблюдение режима работы на компьютере и умение справляться с плохим настроением. И если относительно настроения половина и более детей отметили, что умеют его контролировать, то при работе с компьютером только треть детей соблюдают режим, остальные находятся в группе риска по формированию социального здоровья.

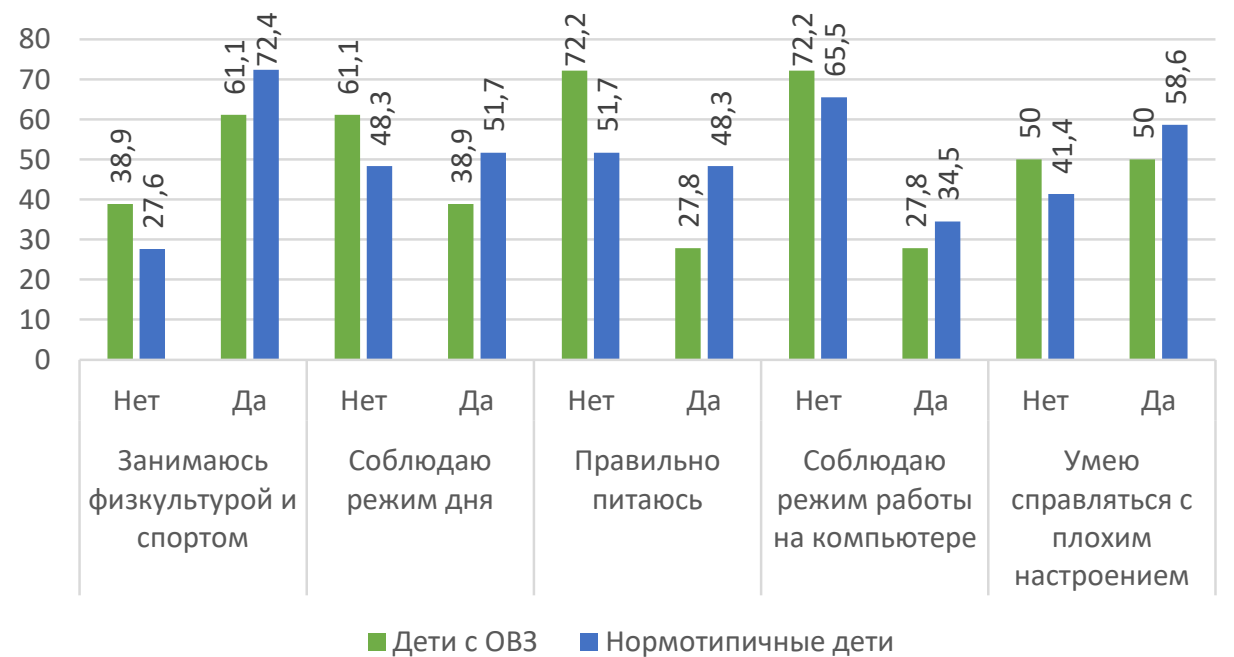

Рисунок 2. Что ты делаешь для того, чтобы быть здоровым (в \% от числа опрошенных) 


\section{Образование.}

Несмотря на заметное превалирование у детей с ОВ3 факторов риска социального здоровья, благодаря реализации адаптированных основных общеобразовательных программ в образовательных организациях успеваемость детей с OB3 сопоставима с успеваемостью детей, обучающихся по основным программам. В большинстве случаев дети оценивают свою успеваемость на «4» и «5».

Отношение в семье и со сверстниками.

Важным элементом социального здоровья является правильные взаимоотношения ребенка и родителя. Исследование показало, что дети с ОВ3 реже рассказывают родителям о своих успехах и трудностях реже $(61,1 \%)$, чем нормотипичные дети $(86,2 \%)$. Около $10 \%$ детей с ОВ3 не делятся с родителями своими переживаниями и радостями.

У абсолютного большинства детей есть друзья и нравится общение с одноклассниками. Также около $22 \%$ детей с ОВ3 отметили, что у них один друг и не очень нравятся взаимоотношения с одноклассниками, что создает предпосылки к социальной изоляции этих школьников.

\section{Поведенческие и средовые риски.}

К поведенческим и средовым рискам в своем исследовании мы отнесли отношение детей к курению, употреблению алкоголя и наркотиков. Анализ данных показал, что абсолютное большинство испытуемых (80,9\%) отрицательно относятся к употреблению наркотиков. Также большинство детей отрицательно относится к курению $(63,8 \%)$ и употреблению алкоголя $(76,6 \%)$. Однако стоит отметить, что 5,6\% детей с ОВ3 выявили положительное отношение к алкоголю $(0,0 \%$ нормотипичные дети) и $16,7 \%$ - к курению (10,3\% нормотипичные дети). И это может быть основой для формирования здоровьеразрушающих привычек в более старшем возрасте.

Самооценка детьми уровня своего благополучия.

Для самооценки детьми уровня своего благополучия была адаптирована методика «Лесенка» (В.Г. Щур) [7]. Детям предлагалось отметить ступеньку (цифру), которая лучше всего отражает их положение на этой лесенке. Где самая верхняя ступенька лестницы - это 10 баллов, т.е. живется очень хорошо, а нижняя ступенька это 0 , т.е. живется очень плохо.

При анализе данных разделили полученные ответы на три уровня по степени самооценки опираясь на основную методику. Завышенная самооценка (10, 9, 8 ступеньки) чаще всего характерна для детей младшего школьного возраста и является возрастной нормой. Это связано со слабо развитой рефлексией (способностью анализировать свою деятельность и соотносить мнения, переживания и действия с мнениями и оценками окружающих). Адекватная самооценка (7, 6, 5 ступеньки) - у ребенка сформировано положительное отношение к себе, он умеет оценивать себя и свою деятельность. Это нормальный вариант развития самооценки. Низкая и очень низкая самооценка $(4,3,2,1,0$ ступеньки) может формироваться по разным причинам. Иногда у ребенка самооценка занижается ситуативно (на момент опроса могло, что-то произойти, например, ссора с товарищем, неудача на уроке), в этом случае через несколько дней самооценка может выправиться и стать более высокой. Более серьезным является наличие стойких мотивированных ответов ребят с ощущением «я плохой». Опасность этой ситуации в том, что низкая самооценка может остаться на всю жизнь и не позволит раскрыться способностям и возможностям ребенка. Выбранные очень низкие позиции на «лесенке» ситуацию школьной дезадаптации, личностного и эмоционального неблагополучия.

Исследование показало, что у большинства детей завышенная и адекватная самооценка, что является нормой, также были выявлены единичные случаи низкой и очень низкой самооценки у детей (табл. 1). 
Таблица 1

Самооченка детьми уровня своего благополучия

\begin{tabular}{|c|c|c|c|}
\hline & Дети с ОВЗ, в \% & $\begin{array}{c}\text { Нормотипичные } \\
\text { дети, }, \%\end{array}$ & Всего, в \% \\
\hline Завыменная & 50,0 & 69,0 & 61,7 \\
\hline Адекватная & 44,4 & 27,6 & 34,0 \\
\hline Низкая и очень низкая & 5,6 & 3,4 & 4,3 \\
\hline Всего & 100,0 & 100,0 & 100,0 \\
\hline
\end{tabular}

Семьям, где выявлены 3 и более факторов риска социального неблагополучия (22,3\% детей с OB3; 6,8\% нормотипичных детей), необходима помощь со стороны социальных педагогов, учителей для смягчения или ликвидации факторов риска (табл. 2). Таким образом, проведенное исследование показало состоятельность методики по изучению и выявлению группы риска детей по социальному неблагополучию.

Таблийа 2

Число факторов риска

\begin{tabular}{|c|c|c|c|}
\hline Число факторов риска & Дети с ОВЗ, в\% & $\begin{array}{c}\text { Нормотипичные } \\
\text { дети, в } \%\end{array}$ & Всего, в \% \\
\hline 0 & 5,6 & 6,9 & 6,4 \\
\hline 1 & 44,4 & 51,7 & 48,9 \\
\hline 2 & 27,8 & 34,5 & 31,9 \\
\hline 3 & 5,6 & 3,4 & 4,3 \\
\hline 4 & 11,1 & 3,4 & 6,4 \\
\hline 5 & 5,6 & 0,0 & 2,1 \\
\hline Всего & 100,0 & 100,0 & 100,0 \\
\hline
\end{tabular}

Во II блоке оценивался уровень школьной мотивации по Н. Лускановой [6].

Исследование показало, что положительная школьная мотивация (хорошая школьная мотивация и положительное отношение к школе) у детей с ОВ3 составляет $44,5 \%$, что ниже в сравнении с нормотипично развивающимися детьми, у которых положительная мотивация составляет 65,5\%. Больше, чем у половины детей с OB3 $(55,6 \%)$ низкая школьная мотивация (низкая школьная мотивация и негативное отношение к школе), у контрольной группы этот показатель составляет $34,4 \%$ (табл. 3 ). Это свидетельствует о том, что дети с ОВЗ требуют большего внимания со стороны педагогов и семьи для снижения рисков социальной дезадаптации.

Таблица 3

Уровень школьной мотивачии

\begin{tabular}{|c|c|c|c|}
\hline & Дети с ОВЗ, в \% & $\begin{array}{c}\text { Нормотипичнье } \\
\text { дети, в \% }\end{array}$ & Всего, в \% \\
\hline Хорошая школьная мотивация & 5,6 & 10,3 & 8,5 \\
\hline Положительное отношение к школе & 38,9 & 55,2 & 48,9 \\
\hline Низкая школьная мотиващчия & 50,0 & 31,0 & 38,3 \\
\hline Негативное отнотение к школе & 5,6 & 3,4 & 4,3 \\
\hline Всего & 100,0 & 100,0 & 100,0 \\
\hline
\end{tabular}

Таким образом, в представленном материале показаны основные особенности компонентов социального здоровья детей с ОВЗ. Полученные данные могут быть использованы для определения направления психолого-педагогического воздействия коррекционными педагогами и учителями начальных классов при формировании социального здоровья детей младшего школьного возраста с ОВ3.

$* * *$

1. Выготский Л.С. Основы дефектологии / Л.С. Выготский. - СПб.: Лань, 2003. - 654 с.

2. Голицина Н.В. Профилактика нарушений социального здоровья как условие социализации детей с ОВ3 / Н.В. Голицина // Череповецкие научные чтения. - Череповец, 2014. - C. 42 - 45. 
3. Денисова О.А. Социальное развитие детей с ограниченными возможностями здоровья: угрозы и перспективы решения в региональном контексте / О.А. Денисова, О.Л. Леханова // Научный электронный архив. URL: http://econf.rae.ru/article/6388 (дата обращения: 14.09.2021)

4. Денисова О.А. Угрозы социального развития детей с ограниченными возможностями здоровья в семейной среде / О.А. Денисова, О.Л. Леханова, Р.А. Самофал, Н.В. Голицина // Вестник Череповецкого государственного университета. - 2013. - № 3 - 1 (49). - С. 105 - 108.

5. Дружинин Р.О. Социальное здоровье детей: сущность и технологии сохранения / Р.О. Дружинин // Социально-экономические явления и процессы - 2011. - № 9 (31). - С. 255 - 259.

6. Методика изучения уровня школьной мотивации H. Лускановой. URL: https://www.sites.google.com/site/psistd/diagnostika/2-1.

7. Щур, В.Г. Методика изучения представлений ребенка об отношениях к нему других людей / В.Г. Щур // Психология личности: теория и эксперимент: сб. науч. тр. - Москва: Изд-во АПН, 1982.

8. Ainscow, M. Developing Inclusive Education Systems: The Role of Organisational Cultures and Leadership. / M. Ainscow, A. Sandill // International Journal of Inclusive Education. - 2010. - № 14 (4). - P. 401 - 416. doi:10.1080/13603110802504903.

9. Duquette, C. Persistence in high school: Experiences of adolescents and young adults with fetal alcohol spectrum disorder / C. Duquette, E. Stodel, S. Fullarton, K. Hagglund // Journal of Intellectual \& Developmental Disability. - 2006. - № 31 (4). - P. 219 - 231.

10. Duquette, C. Secondary school experiences of individuals with foetal alcohol spectrum disorder: Perspectives of parents and their children / C. Duquette, E. Stodel, S. Fullarton, K. Hagglund // International Journal of Inclusive Education. - 2007. - № 11 (5-6). - P. 571 - 591.

11. Flem, A. Inclusion in Norway: A study of ideology in practice / A. Flem, C. Keller // European Journal of Special Needs Education. - 2000. - № 15 (2). - P. 188 - 205.

12. Grima-Farrell, C. R. Bridging the Research-to-practice gap: A Review of the Literature Focusing on Inclusive Education / C. R. Grima-Farrell, A. Bain, S. H. McDonagh // Australasian Journal of Special Education. - 2011. - № 35 (02). - P. 117 - 136. doi:10.1375/ajse.35.2.117.

13. Lindsay, G. Educational Psychology and the Effectiveness of Inclusive Education/Mainstreaming / G. Lindsay // British Journal of Educational Psychology. - 2007. - № 77 (1). - P. 1 - 24. doi:10.1348/000709906X156881.

14. Pijl, S. J. Students with Special Needs and the Composition of Their Peer Group / S. J. Pijl, E. M. Skaalvik, S. Skaalvik // Irish Educational Studies. - 2010. - № 29 (1). - P. 57 - 70. doi:10.1080/03323310903522693.

15. Taylor, M. Difficulties in initiating and sustaining peer friendships: Perspectives on students diagnosed with ADHD / M. Taylor, S. Houghton // British Journal of Special Education. - 2008. - № 35 (4). - P. $209-19$.

\section{Нестеренко В.Г., Матвиенко Л.М. Секрет успеха подготовки учителя в Финляндии}

Волгоградский государственный сочиально-педагогический университет (Россия, Волгоград)

doi 10.18411/gq-15-10-2021-07

\section{Аннотация}

Представлен анализ процесса организации педагогического образования в Финляндии. Уточнены особенности построения обучения с целью обеспечения высочайшего качества программ подготовки учителей; строжайшего отбора в педагогические вузы; организации педагогической практики студентов; многоуровневого оценивания качества готовности выпускников к работе в школе; политики государства в области постдипломного образования учителей. Предложено учесть финский опыт педагогического образования в России.

Ключевые слова: высококвалифицированный педагог, процесс отбора учителей, стратегии обучения и учебные планы, педагогическая практика, обучение в течение жизни.

\section{Abstract}

Presented analysis of the teacher's training process in Finland. Clarified the features of building education courses with the aim of ensuring the highest quality teacher's training programs, rigorous selection for entry to teacher education courses, practical experience 